\title{
Not Surprising: Patients Not Engaged and Not Using Public Healthcare Quality Information
}

\author{
Durhane Wong-Rieger ${ }^{1}$
}

Published online: 28 January 2016

(c) Springer International Publishing Switzerland 2016

Upon reading the paper published in this issue of The Patient: Patient-Centered Outcomes Research [1] on public reports for vulnerable populations living with diabetes mellitus, I reacted with surprise to the observation that "patients have not been systematically engaged in the development, design, and dissemination of publicly available reports on healthcare quality and health information." In reality, the disenfranchisement goes far beyond the vulnerable or marginalized populations, although the repercussions are heightened with vulnerable groups. Paradoxically, there is growing evidence and agreement that patients who are engaged and participate in managing their own healthcare achieve better outcomes [2]. Moreover, patients everywhere are increasingly expected to take an active role in making informed decisions about their healthcare and to take shared responsibility for managing their health condition, especially chronic conditions such as diabetes, arthritis, and cardiovascular conditions. However, we have less confidence and scant evidence that "a broad spectrum" of patients is actually informed, engaged, and empowered to participate as partners. "Despite this encouraging evidence, self-management is the least implemented and most challenging area of chronic disease management" [3].

Why is there such a gap between the seemingly consensual common sense of the value of patient engagement and patient participation in the real world? According to some critics, "if patients are not engaged, it's because we

Durhane Wong-Rieger

durhane@sympatico.ca

1 Institute for Optimizing Health Outcomes, 151 Bloor Street West, Suite 600, Toronto, ON M5S 1S4, Canada as the healthcare system have not been effective in engaging them" [4]. More importantly, to make good choices, it is essential that patients have access to quality information not only about "best practices" on how to manage their condition but also practical information about the options available to them and how to find the resources and support needed.

So, while governments are increasingly mandating healthcare providers to monitor, measure, and make publicly available indicators of healthcare quality, performance, and outcomes $[5,6]$, there is a paucity of research as to (a) how (if) patients are using this information and (b) whether it is even relevant to them. Indeed, the research emerging is that "quality indicators" collected by hospitals and other healthcare systems are not useful in guiding patients to the right healthcare provider, the right treatment options, and the right facility $[7,8]$.

What are the barriers to patients having access to the information and resources that would foster patient engagement? And what are health systems doing about it?

One solution is to make information more accessible to patients. The Leapfrog Group, for example, is challenging the status quo whereby "detailed information about products such as TV's, cars, and computers is far easier to find than information about hospitals or your doctor" [9]. However, it is not clear that the "self-reported" survey data (including items such as computerized ordering of medicines or length of stay) provide most patients with the information to make an informed decision. Nor do websites posting patient ratings of doctors appear to have much influence [10].

Another option is to invite patients to serve on hospital and other health system advisory boards. The Health Care Advisory Board offers strategies, solutions, and a toolkit 
for engaging patients, mostly towards developing policies and programs for the primary care team to support patients in self-management activities [11]. One of the best examples of patient engagement across multiple levels of practice, advisory, and policy boards is the British Columbia (Canada) Patients as Partners program. This is a provincewide initiative that recruits, trains, and supports patient advocates to participate in various types of healthcare boards and initiatives and, importantly, trains the committees and boards to work effectively with patient advocates [12]. The initiative identifies three domains for patient engagement: individual care, program and service design, and system and community. While definitive evaluation data are yet to be produced, the impact on boards, patient members, and products is already evident in specifically addressing the needs of patients.

Overall, the potential for delivering information directly to patients that would support their making informed health decisions and more effectively self-managing health conditions is very much needed and desired by healthcare providers and patients alike. However, there is a large gap in the relevance and accessibility of the information being generated, and, in part, this reflects the lack of patient involvement in the design, development, and dissemination of information. This is especially acute for vulnerable or marginalized patient subgroups and deliberate efforts to solicit input and to facilitate involvement are necessary.

\section{Compliance with Ethical Standards}

Conflict of interest disclosures The author has completed and submitted the Conflict of Interest Disclosure Form, and none were reported.

Funding/support No sources of funding were reported.

\section{References}

1. Longo DR, Crabtree BF, Pellerano MB, Howard J, Saver B, Hannan EL, et al. A qualitative study of vulnerable patient views of type 2 diabetes consumer reports. Patient. doi:10.1007/s40271015-0146-8 (Epub 7 Nov 2015).
2. California Healthcare Foundation. Motivating change: innovative approaches to patient self-management. Nov 2007. http://www. chcf.org/ /media/MEDIA\%20LIBRARY\%20Files/PDF/PDF\% 20M/PDF\%20MotivatingChangeSelfManagementIB.pdf. Accessed 12 Nov 2015.

3. Coleman MT, Newton KS. Supporting self-management in patients with chronic illness. Am Fam Physician. 2005;72(8): 1503-10.

4. Strategies for Nurse Managers Inc. CE article: patient advisory boards engage patients in their own care. 2015. http://www. strategiesfornursemanagers.com/ce_detail/240432.cfm\#. Accessed 12 Nov 2015.

5. Cardiovascular disease and diabetes: policies for better health and quality of care. OECD Health Policy Studies. Paris: OECD Publishing; Jun 2015. doi:10.1787/9789264233010-en. http:// www.keepeek.com/Digital-Asset-Management/oecd/social-issuesmigration-health/cardiovascular-disease-and-diabetes-policies-forbetter-health-and-quality-of-care_9789264233010-en\#page1. Accessed 12 Nov 2015.

6. Hoo E, Lansky D, Roski J, Simpson L. Health plan quality improvement strategy reporting under the Affordable Care Act: implementation considerations. The Commonwealth Fun; 2012 Apr. http://www.commonwealthfund.org/publications/fund-reports/ 2012/apr/health-plan-quality-improvement-strategy. Accessed 12 Nov 2015.

7. Emmert M, Meier F, Pisch F, Sander U. Physician choice making and characteristics associated with using physician-rating websites: cross-sectional study. J Med Internet Res. 2013;15(8):e187. doi:10.2196/jmir.2702.

8. 2015 National Impact Assessment of the Centers for Medicare and Medicaid Services (CMS) Quality Measures Report. Baltimore: CMS; 2015 Mar 2. https://www.cms.gov/medicare/quality-initiatives-patient-assessment-instruments/qualitymeasures/downloads/ 2015-national-impact-assessmentreport.pdf. Accessed 12 Nov 2015.

9. The Leapfrog Group. Patients. 2015. http://www.leapfroggroup. org/patients. Accessed 12 Nov 2015.

10. Grabner-Kräuter S, Waiguny MK. Insights into the impact of online physician reviews on patients' decision making: randomized experiment. J Med Internet Res. 2015;17(4):e93. http://www.ncbi. nlm.nih.gov/pmc/articles/PMC4408377/?report=printable. Accessed 12 Nov 2015.

11. The Advisory Board Company. 11 insights on engaging patients in ongoing management. Jun 2015. https://www.advisory.com/ research/health-care-advisory-board/studies/2014/the-sharedaccountability-model/study. Accessed 12 Nov 2015.

12. Wilson T. Improving service experience: BC patients as partners. Sep 2008. http://www.rpcu.qc.ca/pdf/english/Key_to_System_ Transformation.pdf. Accessed 12 Nov 2015. 